\title{
II Congresso Sul-Americano de Botânica de Tucumán
}

\author{
(República Argentina)
}

\section{WALTER RADAMES ACCORSI}

Prof. de Botânica Geral e Descritiva da E. S. A. "Luiz de Queiroz"

\section{INDICE}

Seç̧ões do Congresso ............... 139

Aspecto social do Congresso ........... 141

Encerramento do Congresso ............ 142

Principais resoluções do Congresso ........ 142

Excursões botânicas ................ 143

Agradecimentos ................. 154

Bibliografia consultada $\ldots \ldots \ldots \ldots \ldots \ldots \ldots 155$ 
Como é de conhecimento geral, a 1a. Reunião Sul-Americana de Botânica realizou-se no período de 12 a 19 de outubro de 1938, na cidade do Rio de Janeiro, graças ao trabalho e esforços dos seus idealizadores e promotores Dr. Paulo Campos Porto, então Diretor do Instituto de Biologia Vegetal e dos professores Alberto Castellanos e Fernando Rosa Mattos, aquêle do Museu de História Natural de Buenos Aires, êste de Montevidéu. O tradicional Jardim Botânico do Rio foi escolhido para o local do conclave não só porque na ocasião era uma das mais importantes instituições científicas do continente, dedicada exclusivamente a estudos dos múltiplos aspectos da flora, como também, devido às facilidades que oferecia aos congressistas e pelo magnífico aspecto fitogeográfico de suas cercanias.

A 1a. Reunião de Botánicos contou com a adesão de 256 congressistas, participando dela 20 delégaçöes estrangeiras. Foram apresentados 130 trabalhos, abrangendo todos os ramos da Botânica. Pode-se avaliar a importância do que foi o memorável certame, consultando-se os três volumes que integram os seus Anais, dades à publicidade em 1938.

Ao encerrar-se a 1a. Reunião Sul-Americana de Botânica, que adquiriu o caráter de um congresso pela magnitude dos trabalhos discutidos e pela repercussão que despertou nos meios cientifícos internacionais, procedeu-se à escolha da sede destinada à realização da 2.a Reunião, escolha que, por proposta do Dr. Carlos O'Donell e aceita por aclamação, coube à cidade de Tucumán. Todavia, em consequência das injunções decorrentes da última guerra mundial, a instalação do II Congresso SulAmericano de Botânica sòmente se tornou possível dez anos mais tarde, isto é, no período de 10 a 17 de outubro de 1948.

A Comissão Organizadora do Congresso esteve constituida dos seguintes membros: Prof. Dr. Horacio Descole, Diretor do Instituto "Miguel Lillo" e Reitor da Universidade Nacional de Tucumán e Srs. Drs. Alberto Castellano e Carlos O’Donell.

Ao Congresso de Tucumán, que contou com o alto patrocínio do Instituto "Miguel Lillo" e da Universidade Nacional de Tucumán, compareceram delegados da maioria dos países do sul do hemisfério, assim como das Américas Central e do Norte, da Europa, num total de 300 congressistas, entre os quais figuravam as mais destacadas autoridades mundiais em Botânica. Das delegações estrangeiras, a do Brasil foi a maior e se compunha dos botânicos: Prof. Dr. João José Almeida Seabra, da Bahia; Drs. Paulo de Tarso Alvim, Otávio Drumond e A. Grosmann, de M. Gerais; Prof. Dr. Honorio Monteiro Filho, Drs 
L. M. Mello Filho, Romano Milanez, Paulo Campos Porto e João Geraldo Kuhlmann, do Rio de Janeiro; Profs. Drs. Felix Rawitscher e Walter Radamés Accorsi, de São Paulo; padre R. Retz, de Santa Catarina; Prof. Dr. Alarich Schultz, Dr. Petrônio Capparelli e R. P. Rambo S. J., do Rio Grande do Sul. Maior poderia ter sido a representação brasileira, pois já contamos com uma excelente elite de pesquisadores e investigadores que muito enobrecem a "Sciencia amabilis" de Lineu.

A Sessão plenária de abertura do Congresso, iniciadà às 18 horas do dia 10 de outubro, no Salão de Atos da Faculdade de Ciências Culturais e Artes, revestiu-se de caráter solene. Presidiu-a o Prof. Dr. Horacio Descole. Nessa ocasião, os congressistas receberam o distintivo oficial, procedendo-se, a seguir, à chamada nominal dos presentes, ao som do hino nacional de cada país. O discurso de abertura foi pronunciado pelo Dr. Horacio Descole. Em nome dos congressistas falou o Prof. Juan Ibanez Gomez, do Chile, que enalteceu a importância e o significado do certame para o desenvolvimento da Botânica, especialmente para a América Latina.

As 21 horas, no Hotel Savoy, o Govêrno da Província de Tucumán homenageou os congressistas e as autoridades presentes com um banquete, em que tomaram parte cêrca de 400 pessoas.

\section{SECÇOEES DO. CONGRESSO}

- As 11 Secções do Congresso estiveram assim distribuidas :

1a. Seç̧ão : Sistemática das Plantas Vasculares (atuais e fósseiš)

2a. Secção: Sistemática das Plantas Celulares (atuais e fósseis)

3a. Secção: Morfologia e Anatomia. Vegetal

4a. Secção: Fisiologia Vegetal

5a. Seç̧ão: Citologia e Genética

6a. Secção: Geobotânica (Ecologia e Geografia das Plantas)

7a. Secção: Micologia e Fitopatologia

8a. Secção: Hidrobiologia (Âguas continentais e oceânicas)

9a. Secção: Fitoquímica

10a. Secção: Aplicações da Botânica (Agrícolà, Médica, etc.)

11a. Secção: História da Botânica

Ao todo foram apresentadas 128 contribuiçōes científicas, cuja distribuição entre as Seç̧ões foi a seguinté: 
1a. Seç̧ão: Sistemática das Plantas Vascularas ....... 37

7a. Seç̧ão: Micologia e Fitopatologia ............. 20

10a. Seç̧ão: Aplicações da Botânica $\ldots \ldots \ldots \ldots \ldots \ldots \ldots \ldots$

3a. Secção: Morfologia e Anatomia ................ 13

5a. Secção: Citologia e Genética ................. 11

2a. Secção: Sistemática das Plantas Celulares ......... 9

4a. Secção: Fisiologia Vegetal $\ldots \ldots \ldots \ldots \ldots \ldots \ldots \ldots \ldots, 7$

6a. Secção: Geobotânica ........................ 5

9a. Seç̧ão: Fitoquímica ..................... 5

11a. Seç̧ão: História da Botânica .................. 3

8a. Secção : Hidrobiologia $. . . \ldots \ldots \ldots \ldots \ldots \ldots \ldots \ldots \ldots, 2$

A relação acima põe de manifesto quais os ramos da Botânica que, por ocasião do Congresso, maior interêsse despertaram entre os pesquisadores da América Latina. E' interessante salientar, também, que das 37 contribuições discutidas na Secção de Sistemática das Plantas Vasculares, a maioria versou sôbre a vegetação sul-americana.

Os trabalhos e as atividades das diversas Secções desenvolveram-se num clima de alta compreensão e cordialidade. Desta forma, os botânicos reunidos em Tucumán puderam estabelecer excelentes trocas de.idéias, arquitetar planos de trabalho e de pesquisa e sugerir medidas relativas ao desenvolvimento das investigações científicas no campo da Botânica contemporânea.

Como contribuição pessoal, apresentei um trabalho intitulado: "Características Morfológicas, Anatômicas e Citológicas da. Epiderme Inferior da Fôlha das Rubiaceae". Apresentei, ainda um trabalho do Dr. Edgard do Amaral Graner, em colaboração comigo, denominado: Os Gens y3-al (plantas albescentes) e y7 (plantas albinas) do Milho e suas Relações com os Plastídios". Ambos os trabalhos foram aprovados por unanimidade pelo plenário.

A delegação brasileira teve boa atuação em diversas Secçōes do Congresso, notadamente no campo da Fisiologia Vegetal, quer quanto à importância dos trabalhos apresentados, quer quanto à participação nos debates e discussões. Os Profs. Drs Honorio Monteiro Filho e Felix Rawitscher foram alvo de honrosa distinção, cabendo-lhes, respectivamente, a presidência das Secções de Morfologia e Anatomia, e Fisiologia Vegetal.

Além das secções ordinárias, importantes conferências foram pronunciadas por botânicos de renome internacional, os quais focalizaram assuntos do mais alto interêsse científico nos domínios da hodierna Botânica. Fizeram-se ouvir, entre outros, o Prof. Thomaz H. Goodspeed, da Universidade de Berckeley, 


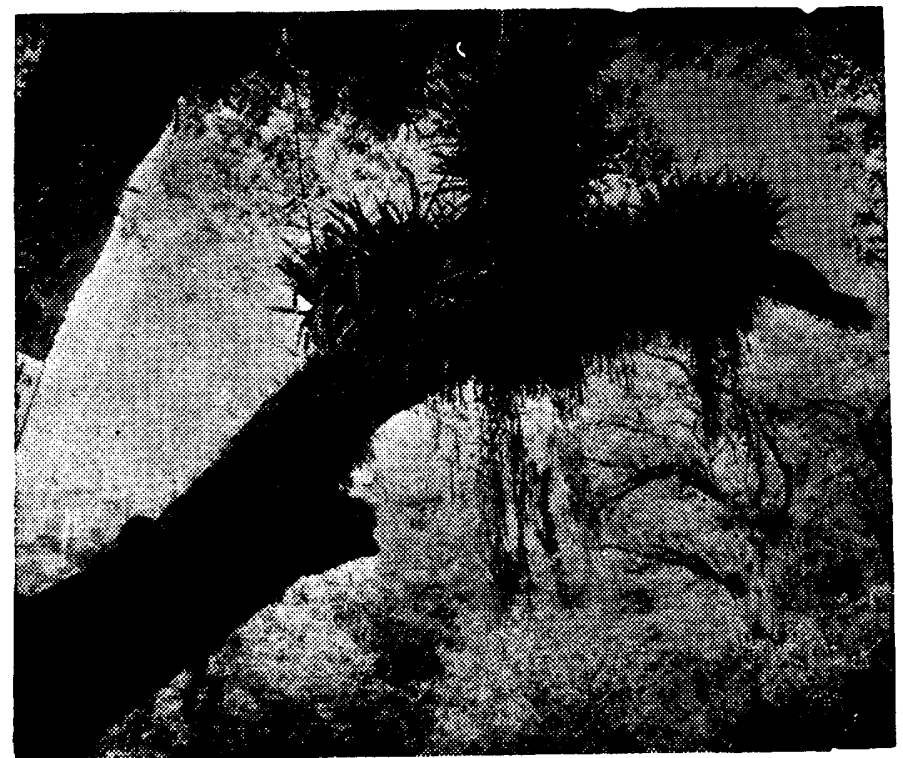

Fig. 1 - Tucumán, Parque de Aconquija. Selva Tucumano-boliviana. Epífitos : Aechmea distichantha Lemaire, Rhipsalis lumbricoides C. Lem., Polypodium sp., piperáceas, musgos e líquens. Gentileza do Dr. Adrian R. Leal 


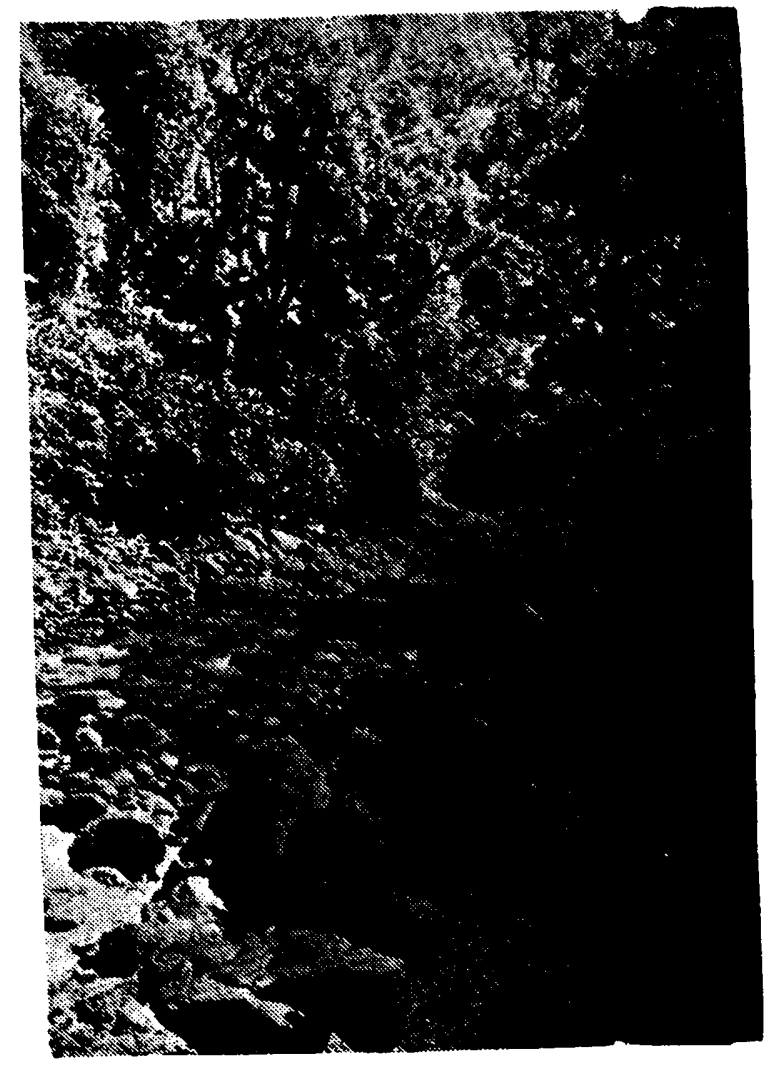

Fig. 2 - Tucumán, subida da Serra de Aconquija. Selva Tucumanoboliviana. 0 rio, em plena vasante, mostra seu leito forrado de pedras. (Original) 
que dissertou sôbre os têmas "Recentes progressos em citogenética" e "As Sequoias da Califórnia"; o Prof. Harold Moldenke, do Jardim Botânico de Nova York, falou sôbre "Plantas citadas na Bíblia" e "Belezas cênicas dos Estados Unidos"; a Sra. Alma Moldenke discorreu sôbre "A Botânica no sistema educacional dos Estados Unidos"; os Profs. Henri Humbert, do Museu Nacional de Ciências Naturais de Paris e Felix Rawitscher, Diretor do Departamento de Botânica da Faculdade de Filosofia da Universidade de São Paulo, abordaram problemas referentes à ecologia tropical, ocupando-se, respectivamente, dos fatores responsáveis pela deterioração dos solos tropicais, principalmente em relação à cultura, em Madagascar e no Brasil. Despertou grande interêsse botânico a magnífica conferência do Prof. Dr. Carlos Skottsberg, representante do Botanical Garden, Gothenburg (Suécia), relativa à "Influência do Cuĩtinente Antártico sôbre a Flora Circumpolar", fartamente ilustrada com projeçõas e gráficos. Finalmente, o ilustrado filólogo Prof. Quirino Franchella, catedrático de línguas da. Universidade Nacional de Tucumán, discorreu com erudição e elegância de estilo a respeito do sugestivo têma : "O Latim de Lineu".

O Prof. Carlos Skottsberg, em nome do Govêrno da Suécia, convidou oficialmente os congressistas presentes em Tucumán para participarem do próximo Congresso Internacional de Botânica, a realizar-se em Estocolmo, em Julho de 1950.

\section{ASPECTO SOCIAL DO CONGRESSO}

De grande valor para a aproximação dos que se dedicam ao mesmo campo de atividades são as reuniões sociais dos congressos científicos. Nesse sentido, a Comissão Organizadora elaborou pomposo programa social, em que transpareceu, mais uma vez, o acentuado espírito de hospitalidade e fidalguia que caracteriza o argentino. Assim, realizaram-se importantes visitas aos principais centros culturais e históricos da capital tucumana, à Universidade Nacional de Tucumán, ao Instituto "Miguel Lillo", à Casa Histórica (onde se proclamou, em 1816, a Independência da Argentina), a Museus, ao magnífico Parque 9 de Julho, um dos mais belos e grandiosos de tôda a república, afora inúmeros passeios pelos lugares pitorescos da cidade e seus arredores. Não faltaram os banquetes oficiais, os almoços campestres, os “cock-tails", muitas vêzes abrilhantados com as belas e tradicionais festas regionais.

A amizade sincera que nasceu atravéz do conhecimento pessoal constituiu a nota mais importante do Congresso, que se transformou, por assim dizer-se, numa grande família. 
Tucumán, pela sua privilegiada situação geográfica e topográfica; pela excelência de seu clima, pelas belezas naturais de suas cercanias, pela invejável uberdade de seu solo, pela civilisação e cultura de sua gente, confirma integralmente a formosa expressão com que a consagraram : "O Jardim da República Argentina".

\section{ENCERRAMENTO DO CONGRESSO}

Em sessão plenária realizada às 10 horas do dia 17 de outubro, no Salão de Atos da Faculdade de Ciências Culturais e Artes, com a presença de todos os congressistas e das altas autoridades civis, militares e governamentais efetuou-se, em caráter solene, o encerramento do grande certame, cujo êxito ultrapassou as melhores espectativas.

Nos amplos e confortáveis salões do Departamento de Educação Física da Universidade Nacional de Tucumán, foi prestada aos participantes do memorável conclave significativa homenagem de despedida, sendo-lhes oferecido um lauto banquete, em que tomaram parie, também, as altas autoridades civis e militares. Foi a mais bela de tôdas as reuniões sociais até então realizadas, devido, em grande parte, ao espírito de solidariedade que dominou durante a fecunda e proveitosa semana de convívio entre os botânicos congregados em Tucumán.

\section{PRINCIPAIS RESOLUÇÕES DO CONGRESSO}

1 - Recomendação às universidades americanas para que incorporem, de forma sistemática, as palavras indígenas, autenticamente originárias do continente, que nomeiam as plantas e as qualificam quase sempre por seus caracteres, propriedades e usos, etc., em tôdas as publicações fundamentais que digam respeito à Botânica Sistemática e Descritiva.

2 - Comunicação às autoridades dos países que participaram do congresso em que se recomenda a criação de observatórios hidrobiológicos nesses países.

3 - Recomendação para que tôda descrição de nova entidade taxonômica seja acompanhada de figuras que ilustrem, pelo menos, seus caracteres essenciais, e que tôda nova entidade seja comparada com outras já conhecidas, estabelecendo-se semelhanças e diferenças.

4 - Considerando que é fundamental que os govêrnos nacionais e de Estados ou províncias estabeleçam um organismo técnico que tenha o conhecimento integral das variedades bo- 
tânicas e hortícolas dos pomares cultivados no país, o que servirá de base para a certificação das plantas que os viveiros oferecem à venda.

5 - Recomendação aos govêrnos representados para que patrocinem, por todos os meios ao seu alcance a criação de um Instituto de Investigações sôbre a Agricultura Precolombiana dos Andes, com sede na cidade de Cuzco, Perú e dentro de um plano de organização internacional.

\section{EXCURSÕES BOTÂNICAS}

Após o encerramento oficial dos trabalhos e atividades do Congresso, foram organizadas importantes excursões botânicas às principais regiôes fitogeográficas do norte do país, destacando-se as caracterizadas por típicas condições climáticas e ecológicas, tais como desertos e oasis, regiōes essas inéditas para a maioria dos botânicos. Visando maior comodidade e facilidade para os excursionistas, as excursões, cuja duração variou entre 8 e 12 dias, realizaram-se em ônibus (cêrca de 6 veículos foram postos à disposição da caravana), providos de todo o equipamento necessário a viagens dessa natureza. 0 itinerário até Salta foi idêntico para todos; todavia, devido às naturais dificuldades de acomodação nas pequenas cidades situadas além de Salta, parte da caravana fez o percurso Santo Antonio de Los Cobres, novamente Salta, Jujuy, etc., e parte regressou a Tucumán, via Métan e Rosario de La Frontera. Participei destá última excursão, integrando o grupo constituido pelọs botânicos Adrian Ruiz Leal, de Mendoza; Teodoro Meyer, prof. de Botânica da Faculdade de Ciências Biológicas, da Universidade de Tucumán; Dr. Roberto Capurro e sra., do Museu Argentino de Ciências Naturais (especialista em Filicíneas); Prof. Augusto G. Schulz, grande conhecedor da flora do Charco Argentino e autor de várias monografias; Prof. Juan R. Báez, do Museu de Entre Rios e do engenheiro-agrônomo Dr. Armando Bonjour, do Instituto Fitotécnico "La Estanzuela", do Uruguai.

As etapas principais do nosso itinerário foram, a partir de Tucumán, as seguintes: Tafí del Valle, El Infiernillo, Amaicha, Santa Maria, El Banado, Colalao del Valle, Cafayatte, Salta (capital da província do mesmo nome), Métan, Rosario de La Frontera e, finalmente Tucumán, num percurso total de cêrca de 1.000 quilômetros.

A excursão teve início na manhã do dia 18 de outubro, com a subida à famosa Serra de Aconquija, situada a alguns quilô- 
metros de Tucumán. A altura média da serra, em quase tôda a sua extensão, oscila entre 5.000 e 6.000 metros. Os picos mais altos permanecem cobertos de neve. A densa selva subtropical que a reveste, desde as faldas, é do tipo tucumano-boliviana, úmida, quente, riquíssima de espécies arbóreas. Pelo aspecto geral, a paisagem assemelha-se a certos trechos da Serra do Mar, a caminho da cidade de Santos.

Afim de melhor apreciarmos a composição florística da magnífica selva, fizemos várias paradas, regisirando as espécies que ocorriam à margem da estrada, realizando, ainda, pequenas incursões mata a dentro. Desta forma pudemos anotar, durante a ascensão à Serra, as seguintes espécies: Juglans australis Griseb., planta muito comum no norte da Argentina; a interessante Fumariaceae Boconia frutescens L.; Cuphea sp.; Terminalia triflora (Griseb.) Lillo; Jacaranda mimosifolia D. Don; Tecoma stans Juss.; Tabebuia Avellanedae Lorentz ex Griseb.; Phoebe porphyria (Griseb.) Mez (planta largamente distribuida por tôda a serva subtropical tucumano-boliviana; chega a ter dois metros de diâmetro); Piptadenia excelsa (Griseb.) Lilo; Tipuana Tipu (Benth) O. K. (gigante da selva subtropical tucumano-boliviana; alcança até 30 metros de altura por 1 de diâmetro e é considerada pelo eminente botânico argentino Arturo Burkart, como uma das mais famosas árvores indígenas); Allophyllus edulis (St. Hil.) Radk. (muito frequente nos bosques da Província Tucumana) e Cupania vernalis Camb. De quando em quands, surgiam aqui e acolá, nos lugares úmidos, touceiras de Equisetum bogotensis H. B. K., que atingiam a 30 e a $40 \mathrm{~cm}$ de altura.

A flora epífita é bem variada e abundante. Entre outras, figuravam as seguintes espécies : Aechmea distichantha Lemaire, Vriesea tucumanensis Mez., Rhipsalis lumbricoides C. Lem., Trichomanes sp., numerosas espécies de Polypodium, Peperomia, além de musgos e líquens, profusamente distribuidos pelas cascas dos troncos e dos ramos. (Fig. 1).

Em cada curva da estrada, traçada ao longo da encosta e margiando o curso de um rio, surgiam panoramas de uma beleza indescritível. O rio encontrava-se em plena vasante, quase sem água; seu leito estava forrado de pedras soltas, de diversos tamanhos e em grande quantidade. (Fig. 2). A rigor, não se trata de um rio, com vida própria. E' mais um canal formado pelo escoamento natural das águas das chuvas, que rolam do cimo da Serra de Aconquija e das águas de infiltração provenientes dos terrenos marginais. Até há poucos anos, a única via de acesso ao alto da serra era um estreito e tortuoso caminho, 


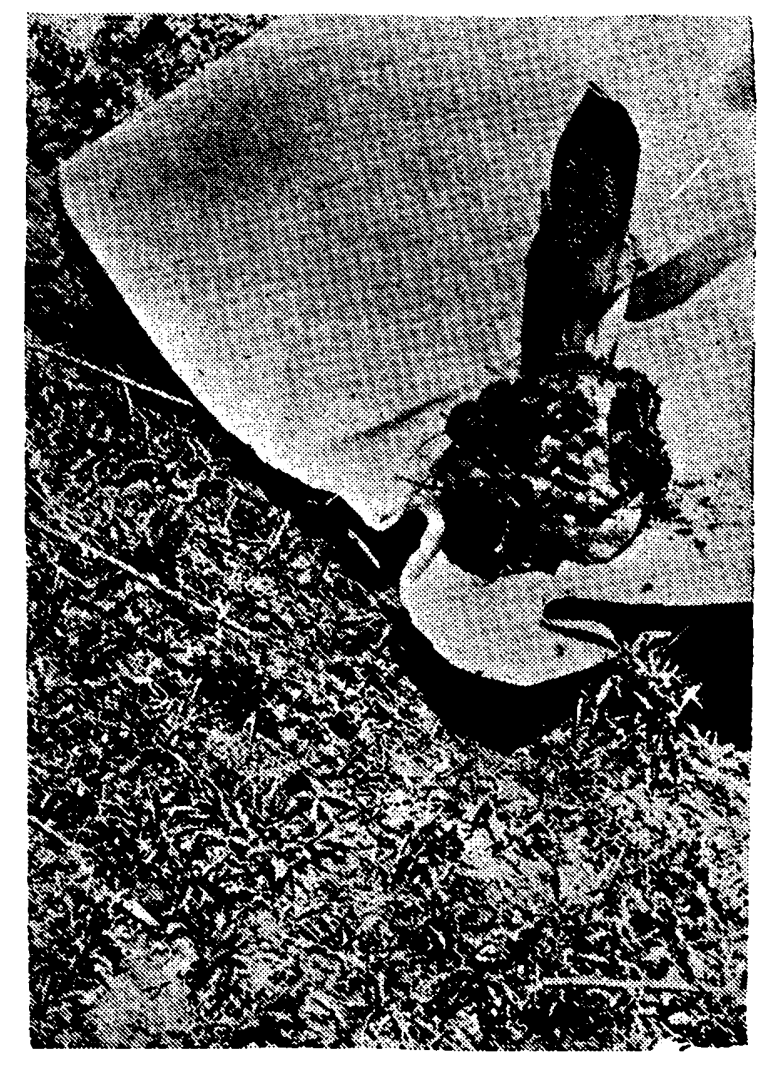

Fig. 3 - 0 "puki" - Arum vermitoxicum Vell., comum no trecho final da Serra de Aconquija. (Original). 


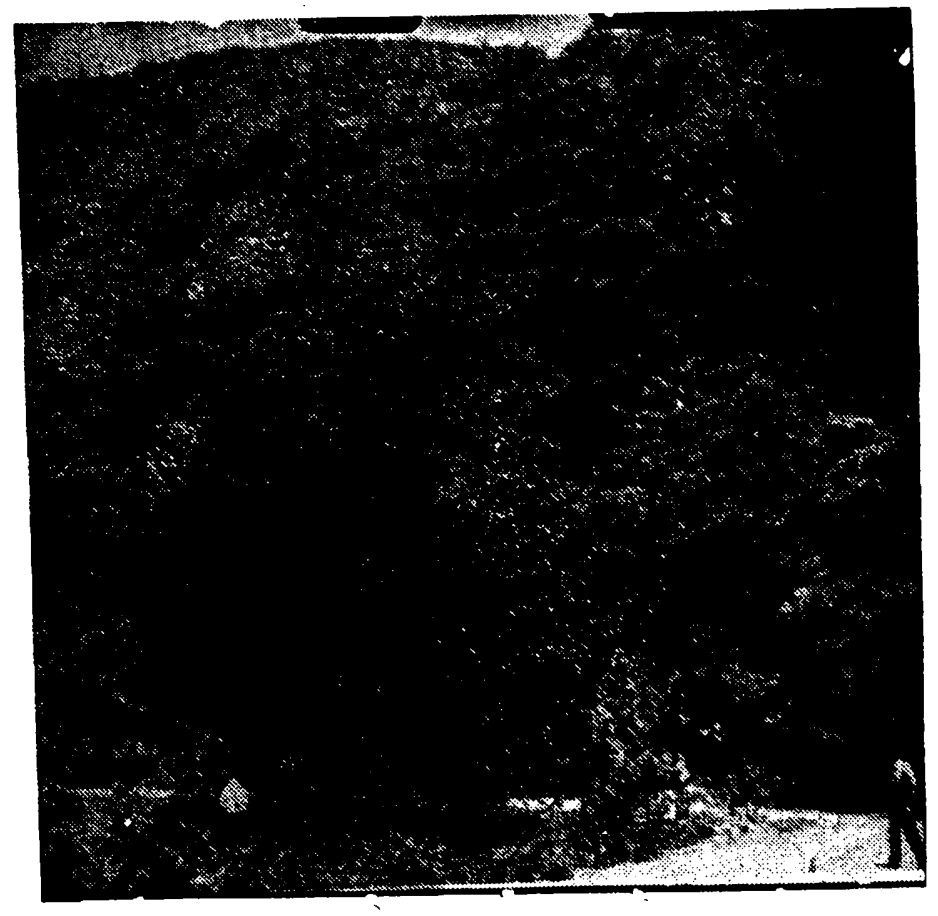

Fig. 4 - Tucumán, entre Los Nogales y La Angostura. Región del Aliso - Alnus jorullensis H. B. K. var. Spachii Regel'. Gentileza do Dr. Andrian R. Leal 
que acompanhava a margem do rio. Nos lugares perigosos e difíceis, o próprio leito do rio servia de passagem aos animais e pedestres.

A medida que íamos ganhando altura, percebíamos que a flora se tornava cada vez mais cerrada, chegando a ser quase impenetrável em certos trechos. Nos barrancos úmidos, nos intervalos situados entre os blocos de pedra, musgos e hepáticas formavam magníficos tapetes virentes. Nas imediações do alto da serra, a vegetação refletia novo aspecto; as árvores distanciavam-se mais umas das outras e exibiam porte menor. O próprio clima era mais sêco e frio. A presença de cactáceas e bromeliáceas na compcsição da vegetação denunciava a transição da selva para o serrado. A essa altura do percurso já se encontrava, com frequência, o "puki" - Arum vermitoxicum Vell., arácea muito curiosa e que se desenvolve, de preferência, nas proximidades das rochas, muito abundantes nessa região. (Fig. 3). O "puki" pəssui um caule subterrâneo, globoso. A princípio, emite a inflorescência envolta em vistosa espata, ligeiramente esverdeada e muito ornamental. Ao depois, aparecem as fôlhas. Entretanto, devido ao fato de as flores adultas exalarem um aroma pouco agradável, o "puki" não é recomendado para jardins.

Terminada a ascensão da serra, a dois mil metros de altitude, avistamos a pitoresca região de Tafí del Valle, magnífico altiplano, com 5 quilômetros de largura, aproximadamente, por 12 de comprimento, ladeado por altas montanhas (prolongamento da Serra de Aconquija), cujos picos mais elevados estavam, também, cobertos de neve. $O$ povoado localiza-se no extremo oposto à entrada do vale, nes proximidades das faldas da montanha.

$E^{\prime}$ interessante e mesmo digno de observação que a vegetação se modifica bruscamente à boca do planalto. A extensa planície e a moldura de serras são completamente despidas de vegetação arbórea natural, em flagrante contraste com a luxuriante mata que vimos durante a subida da serra. Essa região limítrofe reveste-se de importância ecológica porque separa dois tipos de vegetação com características diametralmente opostas. E' possível estabelecer-se um confronto dos fatores ecológicos responsáveis pelos tipos de vegetação que se desenvolvem lado a lado e com composição florística peculiar. Mais adiante farei algumas consideraçōes sôbre os fatores ecológicos dominantes em Tafí del Valle.

Por sôbre as rochas, de todos cs tamanhos e espalhadas por tôda a parte do trecho final da estrada que nos conduz a 
Tafí del Valle, existiam numerosas espécies de musgos (notadamente do gênero Polystichum), líquens, além de várias polipodiáceas.

Podia-se observar, ainda, entre as plantas terrestres, espécies de Senecio, Cestrum (bela solanácea de flores alaranjadas), Taraxacum, Hipolepis (Pteridófita) e o curioso cardo santo - Argemone mexicana L. Todavia, a planta considerada típica dessa região é o "alisso" - Alnus jorullensis H. B. K. var. Spachii Regel. (Fig. 4).

O vale é mais um planalto, que se eleva progressivamente em direção à base das montanhas, que constituem uma imponente muralha natural. Numerosos sulcos e canais, dispostos em várias direções, cavados pelas águas das chuvas provenientes das encostas da serra; cortam o vale. Tôda a água é, em seguida, canalizada para um riacho, que se prolonga até o rio da. Serra de Aconquija.

Notável é a quantidade de pedras distribuidas pelo planalto, a ponto de serem utilizadas pelos moradores do vale na feitura de cêrcas, divisas, etc.

Tafí del Valle possui condições topográficas e ecológicas peculiares. E' uma região assolada por sêcas prolongadas, que chegam a durar meses. Por ocasião da nossa visita, havia sete meses que não chovia. Em consequência, as reservas de água do solo eram escassas e a vegetação pouco desenvolvida. A temperatura, em geral, é baixa, principalmente à noite, chegando a atingir cêrca de $8^{\circ} \mathrm{C}$, mesmo durante o verão. No inverno, chega a cair neve em tôda a planície e a temperatura desce a muitos graus abaixo de zero. Já se registraram temperaturas de $-18^{\circ} \mathrm{C}$. Tódavia, o que mais chama a atenção do botânico é o excepcional regime de ventos, os quais sopram com impetuosidade e constância durante a maior parte do ano. A interação dêsses fatores condiciona o desenvolvimento de uma vegetação tìpicamente xerofítica, quase rasteira (provàvelmente devido à ação permanente dos ventos) e limitada a poucas espécies.

Contrastando com êsse quadro, dominado pelos fatores acima apontados, uma vegetação arbórea desenvolve-se, normalmente, nas gargantas, furnas, vertentes e depressóes da serra que emoldura o vale, exatamente por estar protegida da ação constante dos ventos impetuosos e ser favorecida talvez por um melhor regime dágua. (Fig. 5). Evidencia-se, mais uma vez, em ambientes próximos, a influência dos fatores ecológicos no crescimento e desenvolvimento da vegetação. $\mathrm{Na}$ regiấo da encosta submetida à ação dos ventos medra a gramínea do gênero Sti- 


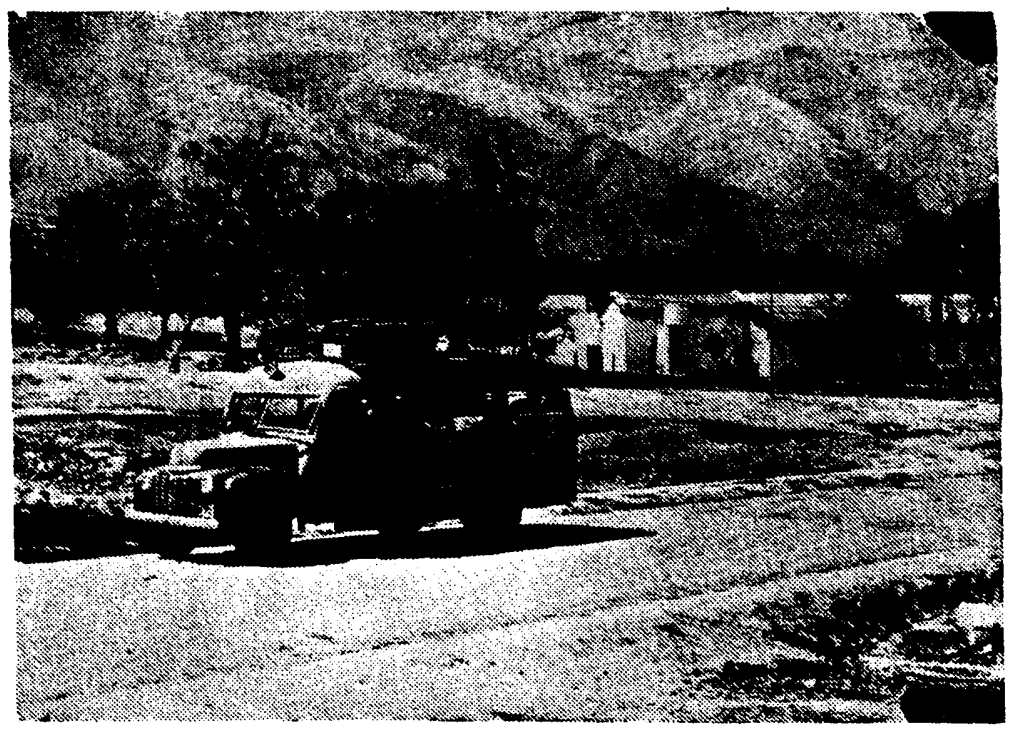

Fig. 5 - Tafi del Valle. Vista parcial da vila e da serra. Distinguem-se perfeitamente as áreas desnudas da encosta (assoladas pelos ventos) das áreas cobertas de vegetação (abrigadas da ação dos ventos). (Original) 


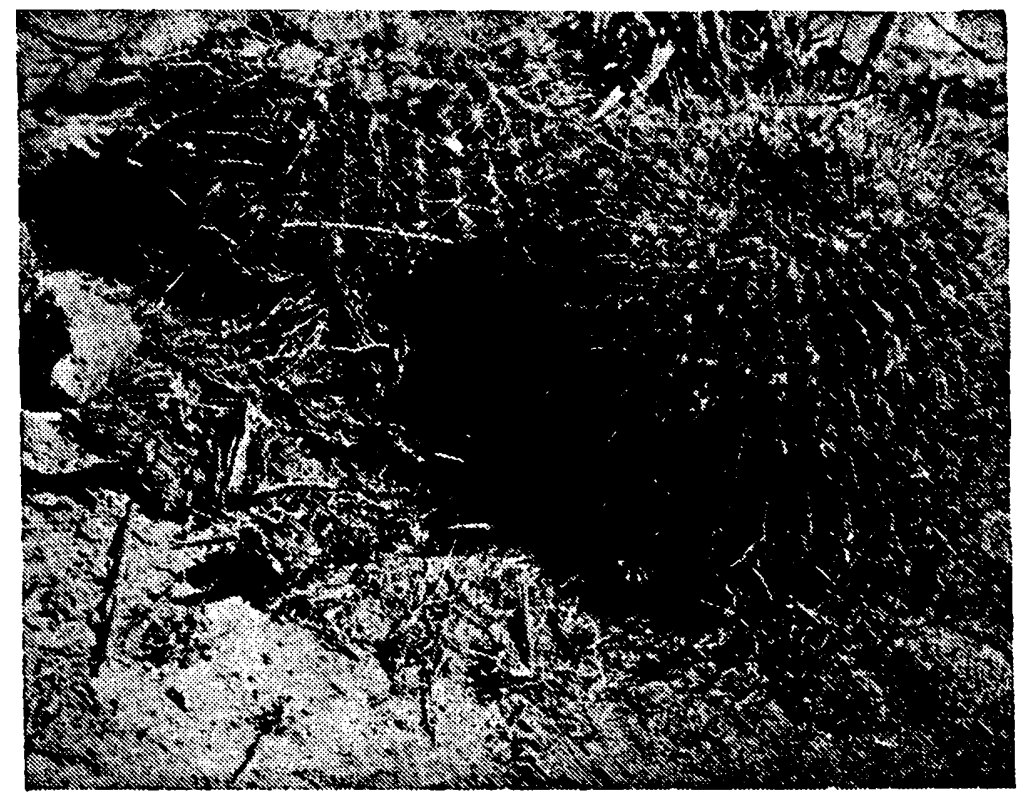

Fig. 6 - Echinopsis (Lobivis) Bruchii (Brit. et Rose) Castell. et Lelong, nov. comb. Cactácea muito ornamental e largamente dispersa por todo o altiplano de Tafí del Valle. (Original) 


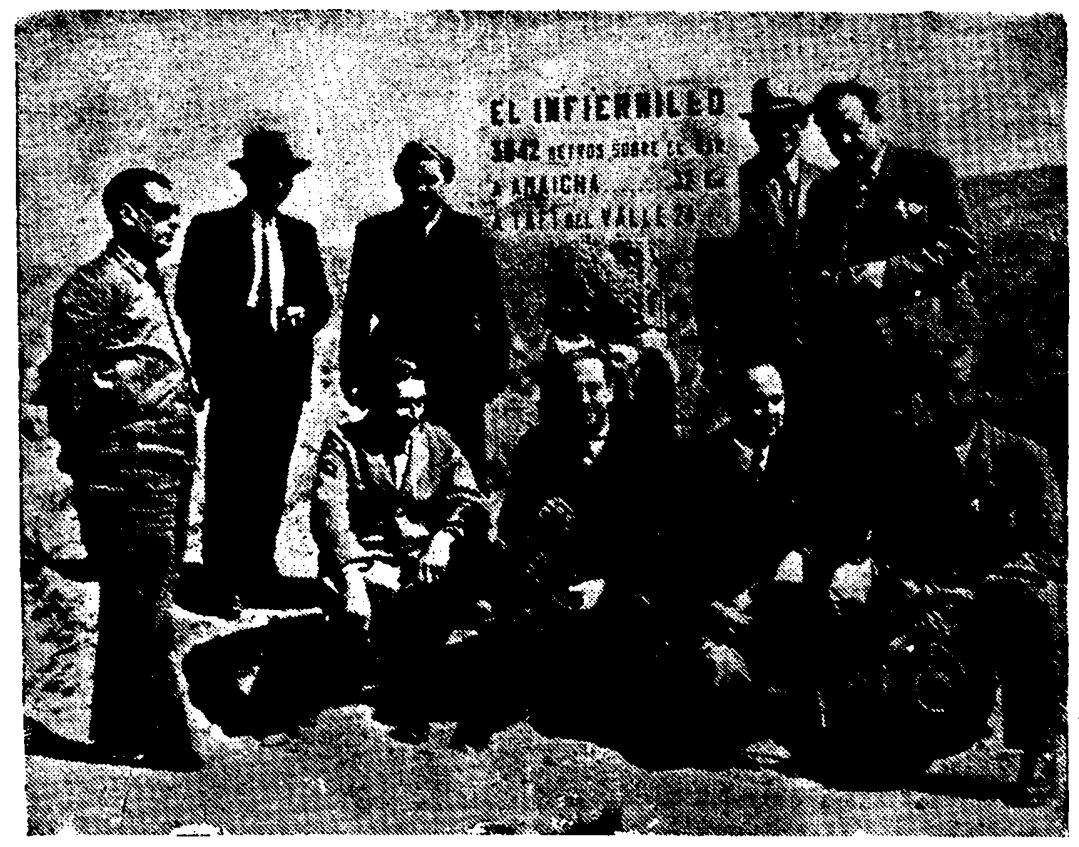

Fig. 7 - El Infiernillo. Botânicos que participaram da 2a. excursão. No primeiro plano e a partir da direita : Drs. Andrian Ruiz Leal, Teodoro Meyer, Roberto Capurro e Prof. Augusto G. Schulz; em pé o cinesifiro do ônibus. No segundo plano e na mesma ordem : Dr. Armando Bonjour, Prof. Juan Báez, sra. Dr. Roberto Capurro e um auxiliar da caravana. (Original) 


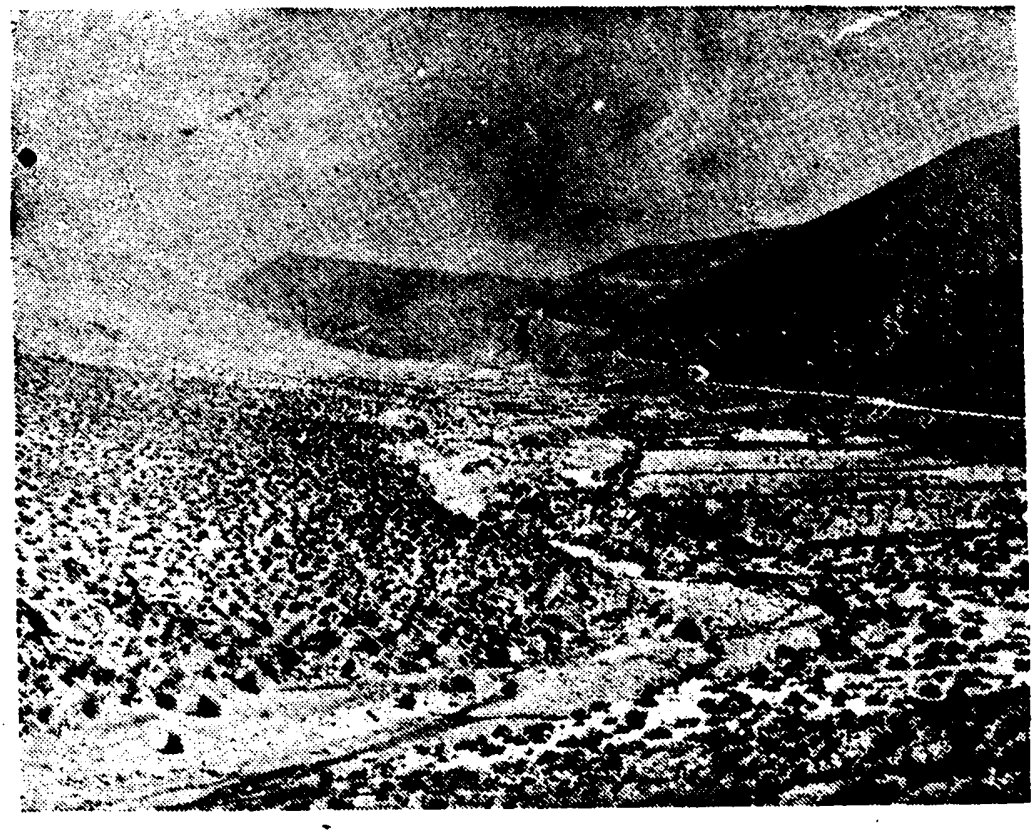

Fig. 8 - Vista panorâmica do Valle de Calchaqui. Região despida de vegetação arbórea. A sêca é tão intensa que o leito do rio está enxuto. (Original) 
pa, a qual, devido à sêca prolongada, adquiriu uma coloração pardacenta, cuja tonalidade muda de acôrdo com a posição do sol.

Após o almoço, empreendemos uma excursão aos pontos mais interessantes de Tafí del Valle, afim de conhecermos a sua composição florística, caracterizada, conforme já assinalei, pelo seu porte reduzido. Tôda a região é pobre em espécies, predominando, entre outras, a conhecidíssima e vulgar composta chilca - Bacharis sp. os belos e interessantes cactos - Echinopsis (Lobivia) Bruchii (Brit. et Rose) Castell, et Lelong, nov. comb. (Fig. 6), a curiosa Euphorbia portulacoides Spreng. (espécie tóxica, com fôlhas semelhantes à beldroega - Portulaca oleracea L.), a ornamental Verbena sp. (muito parecida com a camaradinha - Verbena chamaedrifolia Juss.) além de diversas leguminosas tipicamente xerófitas. Por sôbre as rochas havia notável quantidade de líquens crustáceos. Nos lugares mais úmidos e nos poucos esparsos brejos medravam Equisetum sp., Ranunculus sp., Juncus sp., Nytrophila sp., Hydrocotyle rannunculoides L. f., diversas crucíferas, além de numerosas plantas herbáceas, rasteiras, tudo isso formando associações mais ou menos compactas. A superfície das pequenas poças naturais de água, localizadas nas partes mais baixas do vale, desenvolviase, em quantidade apreciável, a Azolla caroliniana Willd.

Nos quintais das residências particulares, nas ruas da vila, à margem dos pequenos regos dágua, cultiva-se, com bom resultado, a belíssima e ornamental salicácea - Salix Humboldtiana Willd., vulgarmente conhecida por "sauce criolo", "sauce colorado", (Fig. 5) aliás, de ampla distribuição geográfica em tôda a Republica Argentina, em virtude do seu rápido crescimento e da facilidade de sua propagação por estaca.

$\mathrm{Na}$ manhã do dia 19, partimos de Tafí del Valle, rumo à Santa Maria. Cada vez subíamos mais. A vegetação continua a apresentar, nos primeiros quilômetros de estrada, as mesmas características das do vale; contudo, por entre as pedras, fora, por conseguinte, da ação dos ventos, cresciam o "açafrão silvestre" (composta de capítulos vistosos, da côr do açafrão), a chilca - Bacharis, diversas polipodiáceas e selaginelas. O ponto mais alto do percurso é El Infiernillo, com $3.042 \mathrm{~m}$ de altíude. (Fig. 7). O panorama que dele se descortina é deslumbrante. As condições climáticas são aquí mais rigorosas que em Tafí del Valle, pois no inverno neva muito e a temperatura desce a $-22^{\circ} \mathrm{C}$.; os ventos são mais impetuosos. A única planta que cresce nesse ambiente é a gramínea Stipa, que forma extensos prados naturais. Distinguem--se, ainda, nessa região, as ruinas de currais de pedra, de forma cilíndrica, com altura variável, de 
$60 \mathrm{~cm}$ a $1 \mathrm{~m}$, por 3 a $4 \mathrm{~m}$ de diâmetro, construidos pelos Calchaquis, índios pre-colombianos, que habitavam as imediações de El Infiernillo. El Infiernillo é também o limite da província de Tucumán. Daí por diante, começa-se a descer a serra, entrandose na vasta região do Valle de Calchaqui. (Fig. 8). A vegetação já se mostra um tanto modificada, caracterizando-se pela presença de plantas rasteiras, de sub-arbustos, como Bacharis, $\mathrm{Fa}$ biana sp. (solanaceae resinosa) e outras. O terreno vai se tornando progressivamente pedregoso, árido, sêco - com tôdas as características de um verdadeiro deserto. A planta dominante nessa vasia zona montanhosa que se estende por quilômetros e quilômetros, é a imponente cactácea gigante - Trichocereus Pasacana (Web.) Briton et Rose, vulgarmente canhecida na Argentina pelo nome de "cardone". (Fig. 9). Em certos lugares, os "cardones" formam associações naturais que cobrem áreas enormes, chegando a imprimir um aspecto curioso à fisionomia da região, devido à elegância do seu porte e à interessante disposição dos seus ramos colunares, percorridos por sulcos paralelos e longitudinais. A planta adulta, quando bem desenvolvida, chega a atingir de 6 a $8 \mathrm{~m}$ de altura. A sua madeira, leve e resistente, é muito estimada e apreciada, sendo empregada no fabrico de móveis interessantes, tais como cadeiras, mesas, cabides, porta-chapeus de uso regional muito difundido, além de objetos de adorno, grandemente procurados pelos turistas. Na zona rural e campesina a madeira de "cardone" é utilizada na feitura de portas, janelas, madeiramento de ranchos; êstes são coberios, em seguida, com uma camada de Stipa, à semelhança dos nossos ranchos cobertos de sapé - Imperata brasiliensis Trin.

Atravessamos uma região inóspita, em que havia enorme quantidade de pedras, a ponto de formarem camadas de vários metros de altura, em certos lugares. $O$ interessante é que as pedras, de tamanho variável, eram ligeiramente esbranquiçadas e possuiam arestas mais ou menos vivas.

Passamos por Amaicha, pequena localidade situada num verdadeiro deserto. A poucos quilômetros da vila, dispõe-se uma cadeia de morros altos e pelados. A região, além de muito sêca, quente, arenosa é, também, excessivamente pedregosa. A pianta que se dá bem nesse ambiente é o "algarrobo branco" Prosopis alba Gris., havendo ainda outra espécie de algarrobo, - Prosopis chilensis (Mol.) Stuntz.

Chegamos à Santa Maria, segunda etapa da nossa excursão; a vila está localizada numa ampla planície, com $1.200 \mathrm{~m}$ de altitude. Seus arredores são também montanhosos. Os morros 


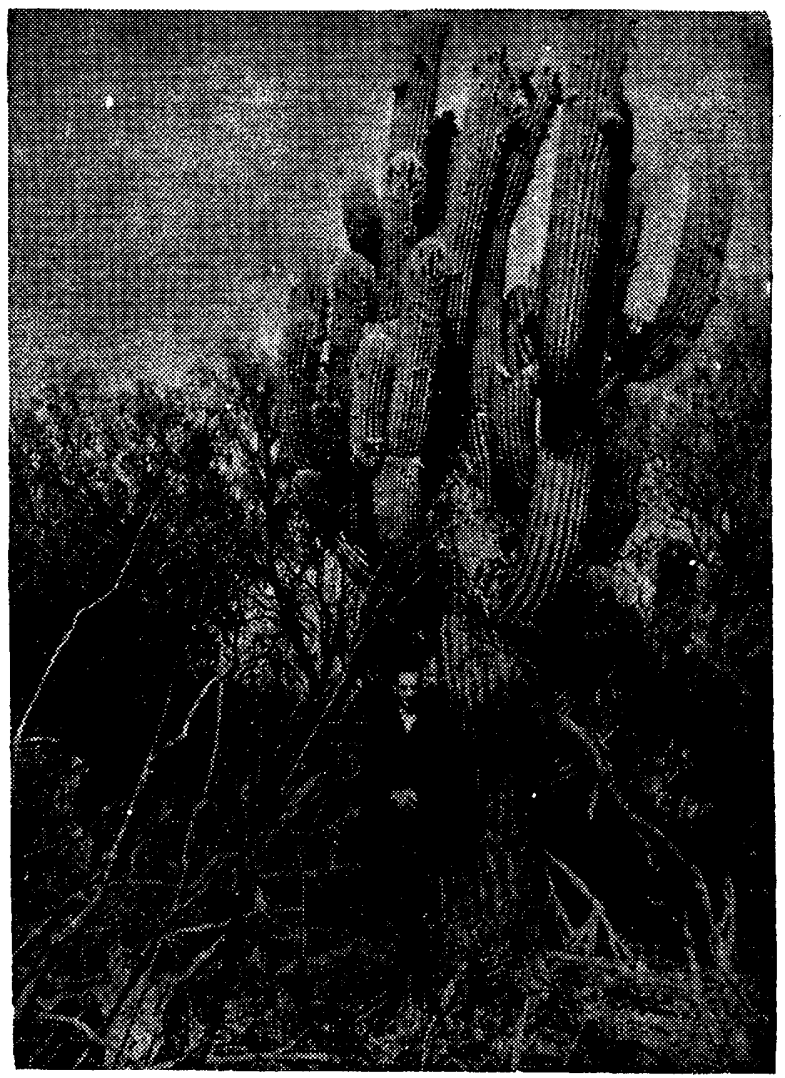

Fig. 9 - Trichocereus Pasacana (Web.) Britton et Rose, o conhecidíssimo 'cardone' das regiões semi-desérticas do norte argentino, em pleno período floral, cercado de uma vegetação morta, devido aos rigores da sêca. Ao lado, o Dr. Roberto Capurro. (Original) 


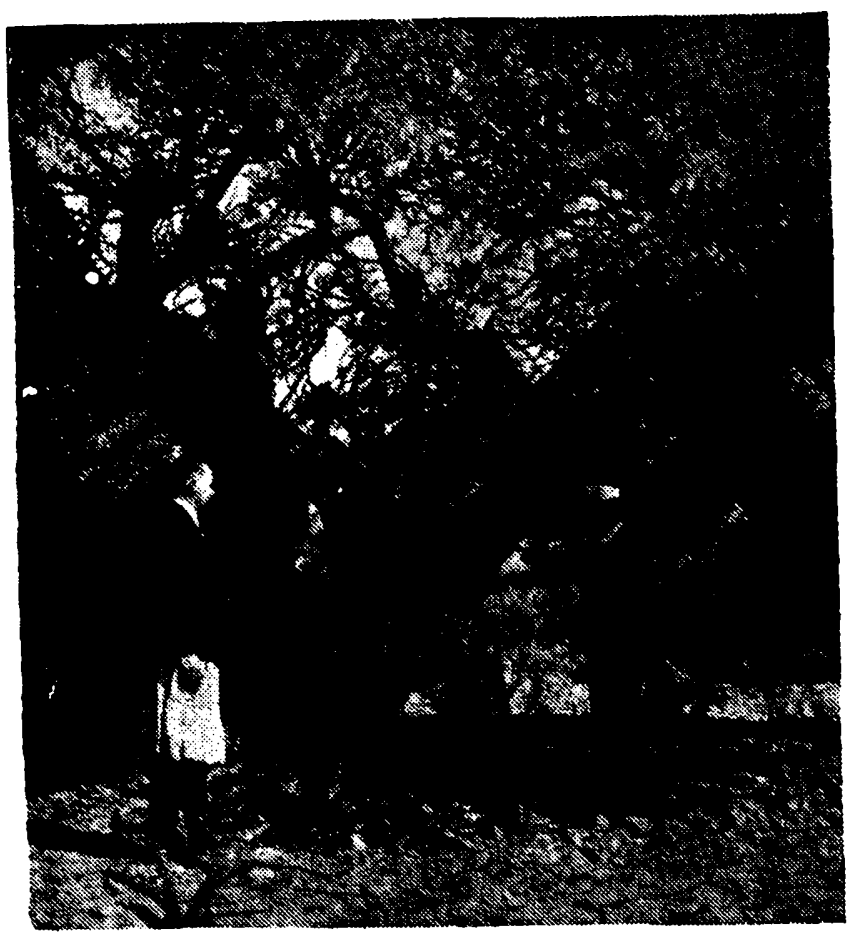

Fig. 10 - Salta, imediaçōes de Tolombon. Um 'algarrobo' secular. No primeiro plano o Prof. Dr. Teodoro Meyer; no segundo o Prof. Juan Báez. Gentileza do Dr. Adrian Ruiz Leal 
são muito altos, sem vegetação e esbranquiçados. O solo de Santa Maria é, em grande parte, salitroso e a vegetação dominante tìpicamente halófita. Numa pequena excursão que realizamos pelos arredores do povoado, pudemos anotar as seguintes plantas : Baccharis sp., Distichlis spicata Greene, Dodonaea viscosa Jacq., Ephedra sp., diversas espécies de leguminosas, entre as quais figurava o "algarrobo", algarrobo branco - Prosopis chilensis (Mol.) Stuntz.

O "algarrobo", planta bastante disseminada por todo o norte argentino, é de grande utilidade e valor. Suas vagens esbranquiçadas, indeiscentes, ligeiramente recurvadas, produzem uma polpa farinácea, de grande emprêgo na fabricação de um pão adocicado, que os pobres da zona rural consomem em larga escala. A sua madeira é muito resistente e durável, sendo utilizada para construções, etc.

Ao longo das estradas, nas cêrcas, vegetava a interessante trepadeira Clematis Hilarii Spreng., espécie dióica muito difundida em tôda a região percorrida. O rio Santa Maria é antes um largo lençol dágua, com alguns centímetros apenas de espessura a deslisar calmamente pela planície, formando aquí e acolá poças e remansos, em cuja superfície se desenvolvia em quantidade enorme a Azolla caroliniana Willd. Em condições desfavoráveis, a Azolla adquire uma tonalidade arroxeada.

No dia 20, pela manhã, deixamos Santa Maria, com destino a Cafayatte, terceiro marco da nossa excursão. A topografia e a vegetação mostram-se bem modificadas com relação às regiōes percorridas anteriormente; todavia, a sêca continuava. As plantas mais frequentes eram: as espécies de Prosopis já mencionadas, os curiosos "cardones" - Trichocereus Pasacana (Web.) Britton et Rose (Fig. 9), e a interessante Opuntia sulphurea Gill. ex Don. Esta última tem hábito prostrado; seus cladódios espinecentes dispõem-se verticalmente sôbre o solo. Onde essa espécie é abundante, o terreno fica dividido em numerosos compartimentos, cujas paredes são constituidas pelos cladódios. Nestas condições, as águas das chuvas são fàcilmente retidas e a sua inflitração no solo fica assegurada. Demais, essa cactácea favorece, em grande parte, a fixação do solo, principalmente numa região assolada por sêcas prolongadas e sujeitas à ação dos ventos. Notável é a quantidade de areia, que chega a formar sequências de dunas muito altas, brancas, nas amplas planícies da região. Sôbre as dunas cresciam diversas plantas rasteiras, em grande quantidade, constituindo um excelente fator de fixação da areia movediça. Pelas cara- 
cterísticas apresentadas, a vegetação é típicamente xerofítica, havendo, ainda, espécies halófitas, em virtude da presença no solo de grandes quantidades de sais. Entre as halófitas pudemos anotar o gênero Salsola e a espécie Atriplex sampa S. Wats.; esta última espécie foi utilizada durante a primeira guerra mundial para a extração de potassa, dada a elevada porcentagem de sal existente em seus tecidos. Das espécies de Prosopis havia uma caracterizada por seu sistema hipógeo excessivamente desenvolvido em relação à parte epígea e recoberta de espinhos.

Tivemos oportunidade de passar por El Banado, povoado habitado por índios, hoje civilizados, da raça Quilmes. Nas proximidades do vilarejo ainda existem as ruinas das malocas primitivas, quando os Quilmes ainda eram selvagens e maus. Visitamos uma escola primária, frequentada quase que exclusivamente por filhos descendentes dos Quilmes. As crianças teem rosto arredondado, pele morena e olhos pretos; em geral são de estatura baixa.

Adiante de El Banado existe outro povoado - Colalao del Valle, cercado de campos cerrados, extremamente sêcos, devido à prolongada estiagem, em cuja composição florística destacavam-se espécie de Prosopis, diversas cactáceas, tais como Opuntia sulphurea Gill. ex Don, Opuntia sp. (com flores avermelhadas e desprovida de espinhos), e uma interessante Ephedra com aspecto de Equisetum. Não encontramos sôbre as plantas o menor vestígio de fungos, líquens e musgos. Tôda a vegetação é xerofítica.

Ao entardecer, atingimos a vila de Cafayatte, situada nas proximidades da serra e a $1.600 \mathrm{~m}$ de altitude, com uma população calculada em 600 habitantes. Cafayatte é um importante centro viticultor. Seus vinhos são afamados em todo o país. 4 flora, conquanto continue xerofítica, mostra-se mais rica em espécies que cs campos de El Banado e de Colalao del Valle. Aproveitando ainda as últimas horas do dia, realizamos uma excursão pelas imensas planícies que contornam a vila. A região é sêca e arenosa. Ausência absoluta de fungos, líquens e musgos. No trecho percorrido fomos anotando numerosas espécies, figurando entre elas as seguintes: Tecoma sp. (bignoniácea ornamental, de flores vermelhas); Bulnesia foliosa Griseb.; Euphorbia Lathyris L. - tártago (planta medicinal); Cereus sp.; Lippia turbinata Griseb., vulgarmente denominada chá dos po- 
bres, muito aromática; Ephedra triandra Tul., muito apreciada pelo gado, como forragem, embora seja encontrada em pequena quantidade; Opuntia sulphurea Gill. ex. Don, cactácea prostrada, formando associações dispostas em círculo; Indigofera anil L. - anileira, além de espécies de Nicotiana, Prosopis, Senecio e outras.

$\mathrm{Na}$ manhã seguinte, dia 21 de outubro, partimos de Cafayatte com destino a Salta, quarta etapa da excursão. A topografia da região modifica-se sensivelmente, à medida que avançamos. Ao longe, delinea-se uma bela serra azulada. As dunas são mais numerosas e maiores que as existentes entre Sta. Maria e Cafayatte e formam longas sequências. As chuvas são, nessa região, muito escassas. Penetramos uma zona de altas montanhas, separadas por grandes planícies. A certa altura do percurso, as montanhas são constituidas de terra vermelha e solta. Um rio largo, mas pouco profundo, banha as planícies limitadas pelas serras. Parece que estamos em presença dos "canyons" da América do Norte. A vegetação, conquanto seja pouco desenvolvida, é relativamente variada, destacando-se, pela frequência, as seguintes espécies: Cassia crassiramer Benth., Gourleia decorticans Gill., de frutos comestíveis, Echinopsis (Lobivia) Bruchii (Brit. et Rose) Castell. et Lelong. nov. comb., Opuntia sulphurea Gill. ex.Don, Philocactus sp., além da interessante e curiosa cactácea Gymnocalycium sp., cujo caule, napiforme, permanece encravado no solo, ficando no rés-do-chão apenas a parte superior. O regíme dos ventos é intenso em tôda a zona.

Atravessamos, agora, uma região exclusivamente montanhosa. As' montanhas são formadas de rochas areníticas, avermelhadas, profundamente erodidas pelos ventos, assumindo, por essa razão, os mais variados e interessantes aspectos, ora de vetustos castelos, ora de fortificações antigas, arruinadas pelo tempo e cercadas de altas muralhas. Panoramas maravilhosos são surpreendidos em cada curva da estrada. $O$ mais sugestivo motivo que se nos deparou foi o de um conjunto semelhante a uma grande cidade em ruinas, com seus templos, fortificaçōes, muralhas, etc. Essas magníficas e soberbas paisagens se estendem por dezenas de quilômetros. A estrada de rodagem contorna a intérmina cadeia de montanhas. Em certos pontos, as encostas são tão abruptas que impressionam o viandante e as curvas, devido à acidentadíssima topografia do terreno, são fechadas e perigosíssimas, marginando, frequentemente, profundos precipícios. 
Em geral, os morros são estéreis, sem vegetação e por isso sujeitos à erosão provocada pelos ventos e pelas águas das chuvas. Pouquíssimas espécies desenvolvem-se em terrenos dessa natureza. Digna de especial menção é a modesta bromeliaceae Dyckia Tweediei Mez., extremamente resistente à sêca e que desempenha importantíssimo papel no tocante à fixação da terra das encostas e das escarpadas, evitando os danosos estragos causados pela erosão. Em menor quantidade vegetam espécies de Prosiopis e a cactácea Opuntia sulphurea Gil. ex Don; esta, pelo fato de ser prostrada e pela disposição dos seus cladódios, constitui ótimo elemento de retenção das águas das chuvas, conforme referências já feitas atrás.

A estiagem era tão intensa que grande parte do rio estava com seu leito enxuto. Contudo, havia lugares no vale com vegetação bem desenvolvida.

Atravessada essa região desértica, a vegetação das montanhas começa a modificar-se lentamente, surgindo, de novo, os interessantes “cardones", Trichocereus Pasacana (Web.) Britton et Rose, que formam numerosas associações naturais, e grupos de "quebracho-blanco" - Aspidosperma quebracho blanco Schlechtd., apocinácea muito comum em tôda a região. A ausência de musgos, fungos e líquens, continua. (Fig. 10).

Nas proximidades de Salta, aparecem com mais frequência os cursos dágua, as boas pastagens, além de algumas culturas de valor econômico. Por essa razão, a flora difere profundamente da que foi vista nas regiōes precendentes, atestando a existência de condições ecológicas mas favoráveis à vegetação.

A cultura do "Guayule", como fonte de latex para fins industriais, não produziu, economicamente, os resultados desejados, motivo pelo qual está sendo abandonada. O mesmo está sucedendo ao Taraxacum kokis-saghiz Rodin, outra composta largamente experimentada, em vários países (notadamente na Rússia), com a mesma finalidade do "Guayule".

Salta, a pitoresca capital da província do mesmo nome, ainda conserva as linhas arquitetônicas que lhe deram os espanhois, quando da sua fundação, embora seja bem visível a influência modernizadora do século XX. (Fig. 11). As casas são de um belo estilo colonial. Em suas cercanias explora-se o petróleo. A agricultura e a pecuária são bem desenvolvidas. 




Fig. 11 - Vista panorâmica de Salta, capital da Provínc1a do mesmo nome. No inverno as montanhas cobrem-se de neve.

De um cartão postal 
Pernoitamos em Salta. Na manhã do dia seguinte, isto é, 22 de outubro, continuamos a excursão, rumo a Métan, penúltima etapa do itinerário escolhido pelo nosso grupo. Os demais excursionistas prosseguiram viagem, visitando Santo Antonio de Los Cobres, Jujuy, Tartagal, etc. A vegetação que se estende entre Salta e Métan também é xerófita, constituida de grandes campos, muito planos; a flora conserva as mesmas características das outras que percorremos anteriormente, maximé quanto às espécies de leguminosas. Em consequência da prolongada falta de chuvas, em tôda a região, havia elevada porcentagem de plantas completamente mortas e inteiramente sêcas. Por sôbre a galharia dessecada, desenvolvia-se enorme quantidade de Tillandsia, de diversas espécies, chegando a substituir, em certas plantas, a antiga folhagem. Nessa região duramente castigada pela sêca, encontramos a bela cactácea Opuntia Quimilo K Schum., comumente denominada "quimillo". Esta espécie difere da Opuntia ficus-indica Mill., com a qual muito se parece, pelas suas flores alaranjadas e pela ausência de espinhos nos seus cladódios. De quando em quando, podíamos assinalar, entre a vegetação, alguns pés de "cardones". Muito frequente é a apocinácea Valetia glabra Link, sub-arbusto de frutos brancos, sucosos e de forma oblonga, além das numerosas bromeliáceas terrestres.

Métan é cidade pequena, com poucos recursos. Nessa época, Métan sofria os rigores de uma sêca fenomenal, pois não chovia normalmente para o desenvolvimento da vegetação hávia quatro anos. A região estava transformada em verdadeiro deserto.

Pela manhã do dia 23, partimos de Métan com destino a Tucumán, têrmo final da excursão. Passamos pela pequenina localidade de Rosario de La Frontera. Os campos começam a exibir uma vegetação mais viçosa e variada, em relação às visitadas durante a viagem. $O$ regime de chuvas é mais regular. Ao longe, avista-se um belo trecho da pre-cordilheira dos Andes, constituido de um série de montanhas azuladas. A vegetação, todavia, continua a ser do tipo xerofítico. Nos campos arenosos vegeta um outro "puki", semelhante ao que vimos quando subíamos a serra de Aconquija, pertencendo, entretanto, à espécie Synandrospadix vermitoxicum Engl. Este "puki" produz, também, uma inflorescência envolta numa espata esverdeada, com manchas brancas, que emerge de um tubérculo subterrâneo, globoso e bem desenvolvido. $\mathrm{Na}$ base do eixo da inflores- 
cência, por conseguinte sôbre o tubérculo, dispõem-se as raízes. As fôlhas surgem bem depois do aparecimento da inflorescência e têm semelhança com as do gênero Anthurium. E' uma espécie interessante, de belo efeito ornamental.

Durante a viagem, fomos surpreendidos por uma grande tempestade de areia, provocada por um vento forte, úmido e frio, a ponto de obscurecer o céu. As tempestades de areia são muito comuns nessas regiões semi-áridas; duram várias horas e cobrem áreas enormes. A impetuosidade dos ventos chega a arrancar arbustos e árvores.

A flora dos campos dessa região mostra um desenvolvimento comparável ao dos nossos campos cerrados. Em sua composição pudemos registrar diversas espécies de cactáceas, em sua maioria do gênero Opuntia, numerosas espécies de Prosopis, a magnifica e ornamental Caesalpinia Gillessi Wall. ex Hook. e a linda Cercidium sp., as quais deveriam fazer obrigatória dos parques e jardins.

Nas proximidades de Tucumán, em Tapia, o Gôverno da Província mantém uma grande reserva florestal natural, constituida de numerosas e importantes espécies, que já teriam desaparecido da região.se não fossem tomadas as necessárias medidas de proteção à flora.

Ao meio dia entrávamos na hospitaleira cidade de Tucumán, após uma belíssima e bem aproveitada excursão botânica, realizada na companhia de excelentes amigos, que foram pródigos em gentilezas e atenções, sempre solícitos na prestação de tôda espécie de informações e esclarecimentos. A êles consigno os meus sinceros agradecimentos.

\section{AGRADECIMENTOS}

Encerrando estas notas, não poderia furtar-me à obrigação de expressar o meu reconhecimento aos distintos colegas Castellanos, Perez Moreau, Ragonezi, Cabrera, Burkart, Sívori, Cozzo, Dimitri, Garese, Krapovickas, Martínez, Piccinini, Milano, O'Donell, snras. Novatti e Soriano, além de tantos outros, pela lhaneza de trato com que me distinguiram. A Delegação Brasileira, que soube manter bem alto as tradições de nossa pátria, o meu abraço fraterno. E ao magnífico Reitor da Universidade Nacional de Tucumán e Diretor do Instituto "Miguel Lillo", Prof. Dr. Horacio Descole - cérebro e coração do II Congresso Sul-Americano de Botânica, o penhor de minha profunda admiração. 


\section{BIBLIOGRAFIA CONSULTADA}

1 - Anais da Primeira Reunião Sul-Americana de Botânica Instituto de Biologia Vegetal. Ministério da Agricultura. Rio de Janeiro, 1938.

2-BURKART, A. Materiales para una monografia del género Prosopis. De Darwiniana, tomo 4, n. 1, 57-128. Buenos Aires, 1940.

3-BURKART, A. Estudos Morfológicos y Etológicos En El Génəro Prosopis. De Darwiniana, tomo 3, n. 1, 27-47. Buenos Aires, 1937.

4-CASTELlanOS, A. Las exploraciones botánicas en la época colonial. Publicacion n. 1, Faculdad de Ciencias Exactas, Fisicas y Naturales. Univ. de Buenos Aires. Revista del Colegio Libre de Estudics Superiores. CXXXVIVII (1943), 411-453.

5-CASTELLANOS, A. Las exploraciones botánicas en la época de la independencia, 1810-1853. Publicacion n. 4 B. Revista "Holmbergia", t. IV, n. 8. 3-14. Buenos Aires, 1945.

6-CASTEllanos, A. e PEREZ MOREAU, R. A. Los tipos de Vegetacion de la Republica Argentina. Publicacion n. 3. De la monografia n. 4, editada por el Instituto de Estudios Geograficos da Universidad Nacional de Tucumán.

7 - CROIZAT, L. Il tipo dell' Euphorbia Portulacoides L. De Darwiniana, t. 6, n. 2, 179-191. Buenos Aires, 1943.

8-DESCOLE, H. Genera et Species Plantarum Argentinarum. Tomus Primus. Universitas Nationales Tucumanensis. Fundatio Michaelis Lillo. Tucumán, MCMXLIII.

9-MEYER, T. Informe de uma excursion botánica a Tilcara y Departamento de Yavi (Prov. de Jujuy) en febrero de 1940. De Memorias Correspondentes a 1940, Instituto Miguel Lillo. Tucumán, 1941.

10-MEYER, T. Los Arboles Indigenas Cultivados en la Ciudad de Tucumán. Miscelanias n. 12. Instituto Miguel Lillo. Tucumán, 1947. 
